\title{
Protein Tyrosine Phosphatase Non-receptor 22 Gene C1858T Polymorphism in Patients with Coexistent Type 2 Diabetes and Hashimoto's Thyroiditis
}

\author{
Funda Bulut ${ }^{1}$, Deniz Erol $^{2}$, Halit Elyas ${ }^{2}$, Halil Doğan ${ }^{3}$, Fethi Ahmet Özdemir ${ }^{2}$, Lezan Keskin ${ }^{4}$ \\ ${ }^{1}$ Department of Medical Biology, Kırıkkale University Faculty of Medicine, Kırıkkale, Turkey

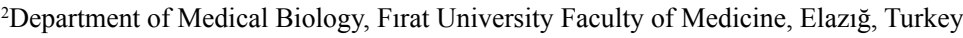 \\ ${ }^{3}$ Department of Internal Medicine, Private Hayat Hospital, Elazı̆̆, Turkey

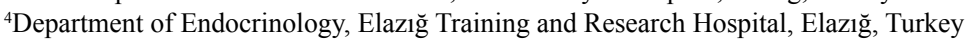

Background: A protein tyrosine phosphatase non-receptor type 22 (PTPN22) C1858T gene polymorphism has been reported to be associated with both Type 2 diabetes mellitus (T2DM) and Hashimoto's thyroiditis (HT) separately. However, no study has been conducted to explore the C1858T polymorphism in T2DM and HT coexistent cases up to now.

Aims: The study aimed to determine whether a relationship exists or not between the PTPN22 C1858T polymorphism and this coexistent patient group.

Study Design: Case-control study.

Methods: Peripheral blood samples from 135 T2DM patients, 102 patients with coexistent T2DM+HT, 71 HT patients and 135 healthy controls were collected into ethylenediaminetetraacetic acid (EDTA) anticoagulant tubes and genomic DNA was extracted. The PTPN22 $\mathrm{C} 1858 \mathrm{~T}$ polymorphism was analyzed using polymerase chain reaction (PCR) restriction fragment length polymorphism (RFLP) methods.

Results: Statistically significant differences were not observed between the patient and control groups. This study demonstrated a statistically significant association between both the CT genotype and the $\mathrm{T}$ allele in the female patient group with coexistent T2DM+HT
(CT genotype: $\mathrm{p}=0.04$; $\mathrm{T}$ allele: $\mathrm{p}=0.045$ ) with a statistically significant association between the CT genotype and the mean values of body mass index (BMI) and free T3 levels (FT3) (BMI: $\mathrm{p}=0.044$ and FT3: $p=0.021)$ that was detected in the patient group with coexistent T2DM+HT. The minor genotype TT was observed in none of the groups in this study. The CT genotype frequency was [number (frequency): 5 (3.8\%), 7 (6.86\%), 5 (7.04\%), 3 (2.22\%), while the T allele frequency was $5(1.86 \%), 7(3.44 \%), 5(3.53 \%)$ and $3(1.12 \%)$ ] in the T2DM, T2DM+HT, HT and control groups, respectively.

Conclusion: Our data suggest that the PTPN22 1858T allele and the CT genotype are associated with increased risk in female patients for coexistent T2DM+HT. The CT genotype was associated with high mean BMI and free T3 values in the patient group with coexistent $\mathrm{T} 2 \mathrm{DM}+\mathrm{HT}$. These results demonstrate that $\mathrm{T}$ allele carriers were more often in the T2DM+HT group than in the T2DM group. Therefore, the combination of T2DM and HT with female gender may have higher $\mathrm{T}$ allele carriage in comparison to the T2DM only and male groups. (Balkan Med J 2014;31:37-42).

Key Words: Hashimoto's thyroiditis, polymorphism, protein tyrosine phosphatase non-receptor type 22 , type 2 diabetes
Autoimmune thyroid diseases and diabetes mellitus exist together more often in comparison to other diseases. The existence ratio increases with age and affects autoimmune diabetics and females the most (1), while thyroid disorders are observed in about $10-15 \%$ of patients with diabetes mellitus and $6 \%$ of non-diabetics (2). Hashimoto's thyroiditis (HT), also known as chronic lymphocytic thyroiditis or chronic autoimmune thyroiditis (3), is the most common autoimmune thyroid disease, affecting up to $10 \%$ of the general population. It is more prevalent in females than in males $(4,5)$. HT is characterized by the development of autoantibodies against thyroid peroxidase (TPO), thyroglobulin, and thyroid stimulating hormone receptor (TSHR) autoantigens. T cells play a vital role in the pathogenesis of the disease by reacting with thyroid antigens and secreting inflammatory cytokines. So, lymphocytic infiltration of the thyroid, gradual loss of thyroid function and goiter are frequently observed (4). Also, a hypoechogenic and inhomogeneous parenchyma can appear in ultrasound observation of the thyroid gland (5).

The observation of thyroid dysfunction in patients with type 1 diabetes mellitus (T1DM) is more frequent than those with type 2 diabetes mellitus (T2DM). Moreover, more than

This study was presented as a poster at the 10 ${ }^{\text {th }}$ National Medical Genetics Congress 20-23 December 2012, Bursa, Turkey. 
one-third of the patients with T1DM eventually develop thyroid dysfunction $(6,7)$. The frequency of thyroid dysfunction in T2DM exceeds that in the general population. The frequency in T1DM has been reported as equal to that in T2DM because of the existence of elderly patients with T2DM (7). Type 2 diabetes is a complex disease diagnosed by elevated blood glucose, insulin resistance and impairment of beta cell function (8). Diabetes affects about 285 million people globally, is extremely common worldwide (9) and will affect 439 million adults by the year 2030 (10). Since $90 \%$ of diabetes mellitus patients have been diagnosed type 2 diabetes, T2DM is the most type of common diabetes mellitus in the world (9).

Hashimoto's thyroiditis and T2DM are multifactorial diseases in which a genetic tendency combines with environmental risk factors to drive disease. Both of these diseases have a strong genetic component $(11,12)$. The concordance of Hashimoto's thyroiditis is reported as $55 \%$ and $0 \%$ in monozygotic (MZ) and dizygotic (DZ) twins (13), whereas the concordance rate of T2DM is approximately $70 \%$ and $20-30 \%$ in $\mathrm{MZ}$ and DZ twins, respectively (14). If one parent has T2DM, the lifetime risk of occurrence the disease is about $40 \%$ in offspring and even higher if the mother is affected; the risk is close to $70 \%$ if both parents suffer from diabetes (14). In view of this strong genetic pattern of T2DM and HT, many candidate genes have been found in association with T2DM and HT. Protein tyrosine phosphatase non-receptor type 22 (PTPN22), CDK5 regulatory subunit associated protein 1-like 1 (CDKAL1), hematopoietically expressed homeobox (HHEX), cyclin-dependent kinase inhibitor 2A/B (CDKN2A/B), insulin-like growth factor 2 mRNA binding protein 2 (IGF2BP2), fat mass and obesity associated (FTO), peroxisome proliferator-activated receptor gamma (PPARG), potassium inwardly-rectifying channel subfamily J member 11 (KCNJ11), transcription factor 7-like 2 (TCF7L2), notch 2 (NOTCH2), calcium/calmodulindependent protein kinase 1D (CAMK1D), a disintegrin and metallopeptidase with thrombospondin type 1 motif, 9 (ADAMTS9), JAZF zinc finger 1 (JAZF1), tetraspanin 8/leucine rich repeat containing $\mathrm{G}$ protein coupled receptor 5 (TSPAN8/ LGR5), and thyroid adenoma associated (THADA) have been defined as related to T2DM and the effects of single nucleotide polymorphisms (SNPs) in PPARG, KCNJ11, solute carrier family 30, member 8 (SLC30A8) have been confirmed as risks for T2DM (11, 15-19). The major histocompatibility complex (HLA), CD40 molecule (CD40), cytotoxic T-lymphocyteassociated protein 4 (CTLA-4), PTPN22, thyroglobulin, and TSH receptor primary genes have been reported to be associated with HT $(12,20)$.

Protein tyrosine phosphatase non-receptor type 22 (PTPN22) on chromosome 1p13.3-p13.1 encodes for the lymphoid tyrosine phosphatase (LYP), which is a $105 \mathrm{kDa}$ protein and a strong suppressor of T-cell activation and T-cell proliferation. Recently, a functional SNP at nucleotide 1858 in co- don 620 of PTPN22 (1858C >T; rs2476601 R620W) has been reported to be associated with T2DM and several autoimmune disorders such as T1DM, rheumatoid arthritis, systemic lupus erythematous, Graves' disease, Addison's disease and HT (16, 17, 21). PTPN22 is one of the genes thought to be associated with both HT and T2DM.

Therefore, this study aimed to determine the extent of the relationship of PTPN22 with T2DM and HT separately, as well as with the coexistence of T2DM+HT in a Turkish population.

\section{MATERIAL AND METHODS}

\section{Participants and study protocol}

The study was approved by the Institutional Ethics Committee of

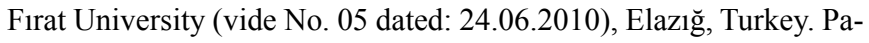
tient and control group clinical data were obtained from the records of Elazığ Private Hayat Hospital (Internal Medicine Department) and Elazığ Training and Research Hospital (Endocrinology Department). Each participant was interviewed and provided written and oral consent before participating in this study.

The study population consisted of four groups: 1- T2DM group of 135 patients ( 83 female/52 male) 2- HT group of 71 patients (68 female/3 male), 3- T2DM+HT group of 102 patients (100 female/2 male) with both T2DM and HT. 4- A control group of 135 healthy volunteer subjects ( 70 female/ 65 male). The data of all participants included a detailed medical history, family history, height, weight, gender, age at the time of study, age of disease onset, clinical findings [for diabetics: body mass index (BMI), glycated haemoglobin (HbA1c) level, postprandial blood sugar and fasting plasma sugar; for Hashimoto's thyroiditis: levels of thyroid stimulating hormone (TSH), free T4 value (FT4) and free T3 value (FT3)] were collected. The clinical and demographic characteristics of the patient groups are shown in Table 1. Participants who had another serious systemic or metabolic disorder were eliminated from the study. Hashimoto's thyroiditis was diagnosed by the presence of hypothyroidism, elevated microsomal or thyroid peroxidase autoantibodies, reduced echogenicity of thyroid ultrasound and serum concentrations of FT3 and FT4. Serum concentrations of FT3, FT4 and TSH were determined by chemiluminescent assay using commercial kits. The normal ranges for serum FT4 and FT3 were 0.8-1.9 ng/dL and 1.8-4.2 pg/mL, respectively. The normal range for serum TSH was $0.4-4.0 \mathrm{IU} / \mathrm{mL}$. For anti-thyroglobulin antibody, less than $35 \mathrm{IU} / \mathrm{mL}$ was considered negative and for anti-thyroid peroxidase (anti-TPO) antibody, less than $40 \mathrm{IU} / \mathrm{mL}$ was considered as negative; these were determined by a chemiluminescent assay. All of the T2D cases were diagnosed according to the medical records and fasting and postprandial plasma glucose levels using American Diabetic Association criteria. The medical records indicate either (1) a fasting plasma glucose level $\geq 126 \mathrm{mg} / \mathrm{dL}$ or $\geq 7.0 \mathrm{mmol} / \mathrm{L}$ after a minimum 12 -h fast or (2) a 2-h post glucose level [2-h oral glucose tolerance test (OGTT)] $\geq 200 \mathrm{mg} /$ 
TABLE 1. Clinical characteristics of the patient groups

\begin{tabular}{lccc}
\hline & T2DM & HT & T2DM+HT \\
\hline $\begin{array}{l}\text { Samples (n) } \\
\text { Male/Female (n) }\end{array}$ & 135 & 71 & 102 \\
Actual age (years) & $55.1 \pm 12$ & $45 \pm 13.5$ & $56.4 \pm 9.52$ \\
Duration of disease (years) & $7.55 \pm 6$. & $1.83 \pm 3.1$ & $\begin{array}{c}\text { DM duration: } 7.2 \pm 5.8 \\
\text { HT duration: } 3.6 \pm 4.4\end{array}$ \\
Age at diagnosis (years) & $47.9 \pm 12$ & $38.4 \pm 13.9$ & T2DM: $49 \pm 9.8$ \\
& & & HT: $52 \pm 9.9$ \\
Hight (m) & $167.4 \pm 11$ & $163.8 \pm 6.6$ & $161.9 \pm 6.49$ \\
Weight (kg) & $80.25 \pm 10.7$ & $71.5 \pm 14.9$ & $81 \pm 12.12$ \\
BMI (kg/m ${ }^{2}$ ) & $28.38 \pm 4.7$ & $26.71 \pm 5.7$ & $31.12 \pm 4.94$ \\
HbA1c (\%) & $8.65 \pm 2.18$ & & $8.07 \pm 1.59$ \\
Fasting glucose (mmol/L) & $181.6 \pm 71.33$ & & $156 \pm 52.19$ \\
postprandial blood & $252.14 \pm 92.50$ & & $252 \pm 70.14$ \\
glucose (mmol/L) & & & \\
TSH (mIU/L) & & $6.47 \pm 13.6$ & $2.79 \pm 5.06$ \\
FT3 (pg M1/L) & & $3.36 \pm 1.08$ & \\
\hline
\end{tabular}

T2DM: type 2 diabetes mellitus; HT: hashimoto thyroiditis; T2DM+HT: type 2 diabetes mellitus and hashimoto thyroiditis coexistent; BMI: body mass index; TSH: thyroid stimulating hormone; FT3: freeT3; HA1C: hemoglobin Alc

TABLE 2. Primary sequences of PTPN22 gene PTPN22 (rs2476601) Sense primer: 5'- ACT GAT AAT GTT GCT TCAACG G-3' PTPN22 (rs2476601) Antisense primer: 5'- TCA CCA GCT TCC TCAACC AC-3'

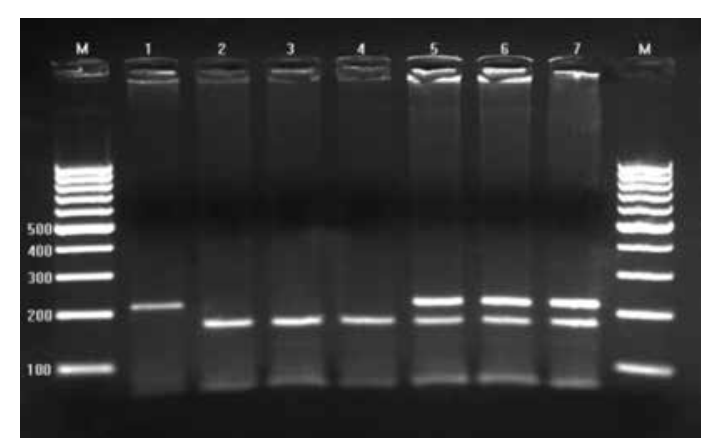

FIG. 1. Agarose gel electrophoresis indicating the presence of the Rs2476601 (C1858T) polymorphism in the protein tyrosine phosphatase non-receptor type 22 (PTPN22) gene.

Column 1: The image of the first PCR intact product samples are undigested (218 bp). Columns 2, 3, 4: RFLP of the CC homozygous (wildtype) variant digested into two bands of 176 and $42 \mathrm{bp}$. Columns 5, 6, 7: RFLP of the CT heterozygous variant digested into three bands of 218 , 176 and $42 \mathrm{bp}$. The TT variant was not detected. M: 100 bp DNA marker.

$\mathrm{dL}$ or $\geq 11.1 \mathrm{mmol} / \mathrm{L}$ on more than one occasion with symptoms of diabetes. Impaired glucose tolerance (IGT) was defined as a fasting plasma glucose level $\geq 100 \mathrm{mg} / \mathrm{dL}(5.6 \mathrm{mmol} / \mathrm{L})$ but $\leq 126 \mathrm{mg} / \mathrm{dL}(7.0$ $\mathrm{mmol} / \mathrm{L})$ or a 2 -h OGTT $\geq 140 \mathrm{mg} / \mathrm{dL}(7.8 \mathrm{mmol} / \mathrm{L})$ but $\leq 200 \mathrm{mg} / \mathrm{dL}$ $(11.1 \mathrm{mmol} / \mathrm{L})$.

\section{Genotyping}

Genomic DNA was extracted from 3 cc of peripheral blood using a commercial kit (Wizard; Promega Corp, Madison, USA) according to the manufacturer's instructions. Polymerase chain reaction (PCR) and restriction fragment length polymorphism (RFLP) were utilized for genotyping PTPN22 gene polymorphisms. The PCR protocol for the detection of this polymorphism was performed according to Zhang et al. (22). PCR reactions were performed at $95^{\circ} \mathrm{C}$ for $5 \mathrm{~min}$ followed by 36 cycles at $95^{\circ} \mathrm{C}$ for $30 \mathrm{~s}$, at $64^{\circ} \mathrm{C}$ for $30 \mathrm{~s}$, at $72^{\circ} \mathrm{C}$ for $30 \mathrm{~s}$, and a final incubation at $72^{\circ} \mathrm{C}$ for $7 \mathrm{~min}$. Using forward and reverse primers (as presented in the Table 2), target DNA was amplified by PCR (Biometra; Göttingen, Germany). After PCR, DNA fragments were digested with a specific restriction enzyme RsaI (RsaI; Fermentas, Hanover, USA): RsaI at $37^{\circ} \mathrm{C}$ overnight. The presence of the CC homozygous (wild-type) genotype was described by two bands at 176 and $42 \mathrm{bp}$, whereas the RFLP of the CT heterozygous variant was characterized by three bands at 218, 176 and 42 bp (as shown in Figure 1). Intact PCR samples before digestion provided a band at 218 bp (as shown in Figure 1). Samples were visualized on a $3 \%$ agarose gel. Ethidium bromide staining was used to detect the amplified fragments.

\section{Statistical analysis}

All analyses were performed using the Statistical Package for the Social Sciences (SPSS 12.0, Chicago, IL, USA). Relationships between parameters were evaluated using Pearson's correlation analysis. The Hardy-Weinberg equilibrium of the genetic distribution was analyzed with the chi-squared $\left(\mathrm{X}^{2}\right)$ test. Differences in genotypic distributions between patients, females and male and controls were evaluated with the chi-squared or Fisher's exact test. Allele frequencies between cases and controls were compared using Fisher's exact test.

Odds ratios (OR) with 95\% confidence intervals (CIs) were used for the assessment of risk factors. Taking into account the both PTPN22 CT and CC genotypes, one-way analysis of variance (ANOVA) was performed to compare the differences in the demographic properties (age, gender, height, weight) among the groups. $\mathrm{P}$ values less than 0.05 were considered statistically significant.

\section{RESULTS}

There were no statistically significant differences among the patients and control groups with regard to the genotypes and allele frequencies ( $p>0.05$; as shown in Table 3 and 4). In this study, the genotype distributions of all groups were in Hardy-Weinberg equilibrium (T2DM, $\mathrm{p}=0.05$; HT, $\mathrm{p}=0.09$; $\mathrm{T} 2 \mathrm{DM}+\mathrm{HT}, \mathrm{p}=0.13$; controls $\mathrm{p}=0.02$ ). The minor genotype TT was not detected in any of the groups. In the T2DM, the CC genotype was found in 130 patients $(96.2 \%)$ and CT in 5 patients $(3.8 \%)$; in the HT cohort, $\mathrm{CC}$ was found in 66 patients $(92.95 \%)$ and CT in 5 patients $(7.04 \%)$; in the T2DM+HT cohort, CC was found in 95 patients $(93.13 \%)$ and CT in 7 patients $(6.86 \%)$; and in the control cohort, CC was found in 132 patients $(97.77 \%)$ and CT in 3 patients $(2.22 \%)$, as shown in 
Table 3. C alelle frequencies were identified as $265(98.14 \%)$, 197 (96.56\%), 137 (96.47\%), 267 (98.88\%), while the T allele frequency was $5(1.86 \%), 7$ (3.44\%), $5(3.53 \%)$ and $3(1.12 \%)$ in the T2DM, T2DM+HT, HT and control groups, respectively (shown in Table 4). T allele frequencies were higher in the HT and T2DM+HT groups compared to the T2DM group.

CC genotype frequencies in females were 78 (94\%), 94 (94\%), $64(94.1 \%)$ and $70(100 \%)$ in the T2DM, T2DM+HT, HT and control groups, respectively. CT genotype frequencies in females were $5(6 \%), 6(6 \%), 4(5.9 \%)$ and $0(0 \%)$ in the T2DM, T2DM+HT, HT and control groups, respectively. C alelle frequencies in females were 161 (97\%), 194 (97\%), 132 (97.1\%) and 140(100\%) in the T2DM, T2DM+HT, HT and control groups, respectively. In males, the $\mathrm{C}$ allele frequencies were $104(100 \%), 3(75 \%), 5(83.3 \%)$ and $127(97.7 \%)$. $\mathrm{T}$ alelle frequencies in females were $5(3 \%), 6(3 \%), 4(2.9 \%)$ and $0(0 \%)$ and in male groups were $0(0 \%), 1(25 \%), 1$ $(16,7 \%)$ and $3(2.3 \%)$ in the T2DM, T2DM+HT, HT and control groups, respectively (shown in Table 5).

Our data suggest that a statistically significant association between both the CT genotype and T allele was detected in females with coexistent T2DM +HT (CT genotype: $\mathrm{p}=0.04$; T allele: $\mathrm{p}=0.045$ ).

When the genotypes of all patients were compared with the demographic characteristics (age, height, sex, weight, BMI, $\mathrm{HbA1C}$, fasting and postprandial blood sugar levels, TSH, FT3, age at onset, duration of disease), their genotypes were not observed in any association $(\mathrm{p}>0.05)$. On the other hand, a statistically significant relationship between the CT genotype and the

TABLE 3. Genotype frequencies of the patient and control groups

\begin{tabular}{lcccccc}
\hline Groups & $\mathrm{n}$ & $\mathrm{CC}$ & $\mathrm{CT}$ & $\mathrm{p}$ & $95 \% \mathrm{CI}$ & $\mathrm{H}-\mathrm{W}$ eq \\
\hline T2DM & 135 & $130(\% 96.2)$ & $5(\% 3.8)$ & 0.722 & $(0.396-7.227)$ & 0.05 \\
HT & 71 & $66(\% 92.95)$ & $5(\% 7.04)$ & 0.127 & $(0.772-14.375)$ & 0.09 \\
T2DM+HT & 102 & $95(\% 93.13)$ & $7(\% 6.86)$ & 0.318 & $(0.141-1.816)$ & 0.13 \\
Control & 135 & $132(\% 97.77)$ & $3(\% 2.22)$ & & & 0.02 \\
\hline T2DM: type 2 diabetes mellitus; HT: hashimoto thyroiditis; T2DM+HT: type 2 diabetes \\
mellitus and hashimoto thyroiditis coexistent; CC: homozygous; CT: heterozygote; n: \\
number; p: p value; H-W eq: Hardy-Weinberg equilibrium; CI: confidence interval
\end{tabular}

mean values of BMI and free T3 (FT3) was observed only in the T2DM+HT patient group (BMI: $\mathrm{p}=0.044$; FT3: $\mathrm{p}=0.021$ ). In this group, the mean BMI values in the $\mathrm{CC}$ and $\mathrm{CT}$ genotypes were 31.4 and 27.5, respectively. The mean values of FT3 in the CC and CT genotypes were 3.285 and 4.176 , respectively.

In the control group consisting of 70 female and 65 male healthy subjects, the average age was identified as 38.62 , while the standard deviation was 13.97.

\section{DISCUSSION}

Some recently published papers have reported islet autoimmunity and inflammation as the two most important mechanisms in the pathogenesis of T2DM (23-26). In one study, young people diagnosed with T2DM were reported to express beta-cell auto-antibodies by 10 to $75 \%$. In another study, in $11 \%$ of young people with clinically diagnosed T2DM, all four auto-antibodies were found (23). Importantly, inflammation is prominent in older cases and inflammatory cytokines such as TNF- $\alpha$, IL-1, IL-6, MCP-1 and IL-8 have been found to take part in insulin signaling pathways and the progression of insulin resistance (24). The insulin resistance observed in T2DM and obesity is closely associated with low-grade inflammation (25). In view of the fact that autoimmunity and the inflammation associated with autoimmunity have been found to contribute to T2DM progression, and since autoimmunity also plays a major role in HT pathogenesis, it was decided to study the PTPN22 C1858T gene polymorphism in these diseases.

TABLE 4. Allele frequencies of the patient and control groups

\begin{tabular}{lccccc}
\hline Groups & $\mathrm{n}$ & $\mathrm{C}$ & $\mathrm{T}$ & $\mathrm{p}$ & $95 \% \mathrm{CI}$ \\
\hline T2DM & 270 & $265(\% 98.14)$ & $5(\% 1.86)$ & 0.72 & $(0.397-7.097)$ \\
HT & 142 & $137(\% 96.47)$ & $5(\% 3.53)$ & 0.13 & $(0.764-3.793)$ \\
T2DM+HT & 204 & $197(\% 96.56)$ & $7(\% 3.44)$ & 0.323 & $(0.807-2.383)$ \\
Control & 270 & $267(\% 98.88)$ & $3(\% 1.12)$ & & \\
\hline
\end{tabular}

T2DM: type 2 diabetes mellitus; HT: hashimoto thyroiditis; T2DM+HT: type 2 diabetes mellitus and hashimoto thyroiditis coexistent; $\mathrm{C}$ : $\mathrm{C}$ allele; $\mathrm{T}$ : T allele; $n$ : number; $\mathrm{p}$ : $\mathrm{p}$ value; CI: confidence interval

TABLE 5. Genotype and allele frequencies of the female and male groups

\begin{tabular}{|c|c|c|c|c|c|c|c|c|c|}
\hline & \multirow[b]{2}{*}{ Groups } & \multicolumn{4}{|c|}{ Genotype } & \multicolumn{4}{|c|}{ Allele } \\
\hline & & $\mathrm{n}$ & $\mathrm{CC}$ & $\mathrm{CT}$ & $\mathrm{p}$ & $\mathrm{n}$ & $\mathrm{C}$ & $\mathrm{T}$ & $\mathrm{p}$ \\
\hline \multirow[t]{4}{*}{ Female } & $\mathrm{T} 2 \mathrm{DM}$ & 83 & 78 (94\%) & $5(6 \%)$ & 0.063 & 166 & $161(97 \%)$ & $5(3 \%)$ & 0.065 \\
\hline & HT & 68 & $64(94.1 \%)$ & $4(5.9 \%)$ & 0.56 & 136 & $132(97.1 \%)$ & $4(2.9 \%)$ & 0.058 \\
\hline & $\mathrm{T} 2 \mathrm{DM}+\mathrm{HT}$ & 100 & 94 (94\%) & $6(6 \%)$ & 0.04 & 200 & 194 (97\%) & $6(3 \%)$ & 0.045 \\
\hline & Control & 70 & $70(100 \%)$ & $0(0 \%)$ & & 140 & $140(100 \%)$ & $0(0 \%)$ & \\
\hline \multirow[t]{4}{*}{ Male } & $\mathrm{T} 2 \mathrm{DM}$ & 52 & $52(100 \%)$ & $0(0 \%)$ & 0.25 & 104 & $104(100 \%)$ & $0(0 \%)$ & 0.256 \\
\hline & HT & 3 & $2(66.7 \%)$ & $1(33.3 \%)$ & 0.16 & 6 & $5(83.3 \%)$ & $1(16.7 \%)$ & 0.167 \\
\hline & $\mathrm{T} 2 \mathrm{DM}+\mathrm{HT}$ & 2 & $1(50 \%)$ & $1(50 \%)$ & 0.11 & 4 & $3(75 \%)$ & $1(25 \%)$ & 0.115 \\
\hline & Control & 65 & $62(95.4 \%)$ & $3(4.6 \%)$ & & 130 & $127(97.7 \%)$ & $3(2.3 \%)$ & \\
\hline
\end{tabular}

T2DM: type 2 diabetes mellitus; HT: hashimoto thyroiditis; T2DM+HT: type 2 diabetes mellitus and hashimoto thyroiditis coexistent; CC: homozygous; CT: heterozygote; C: C allele; T: T allele; n: number; $p$ : p value 
Numerous studies have been performed since Bottini et al. (17) first discovered the influence of the PTPN22 gene on autoimmune diseases (17). PTPN22 is a strong inhibitor of T cell activation and may therefore affect susceptibility to autoimmunity; it has been implicated in a number of autoimmune and inflammatory diseases $(17,27,28)$.

The PTPN22 gene is on chromosome 1p13 and encodes for lymphoid-specific phosphatase (LYP), expressed in T and B lymphocytes. LYP negatively modulates $\mathrm{T}$ cell antigen receptor (TCR) signaling by binding to the $\mathrm{C}$-terminal Src tyrosine kinase (Csk) and directly dephosphorylating the key Src family signaling molecules kinases Lck, Fyn, ZAP-70 and others $(17,27)$. The PTPN22 C1858T polymorphism occurs at an important nucleotide position of LYP where it binds to the SH3 domain of Csk. A tryptophan (W) to arginine (R) exchange at codon 620 of the LYP protein (C1858T SNP) impairs LYP binding to Csk, such that Csk and LYP cannot downregulate TCR signaling. Due to the fact that LYP has the capacity to inhibit TCR signaling, post-translational mechanisms are involved in regulating the function of LYP. However, in contrast to downregulating TCR signaling, this mutation makes the protein a stronger inhibitor of $\mathrm{T}$ cells, because of a gain-offunction mutation (27). This is surprising because the $1858 \mathrm{~T}$ variant is expected to increase T cell activation (as in CTLA4); however, the opposite situation is observed (29). A probable explanation for this may be that a reduced $\mathrm{T}$ cell receptor signal may promote the evasion of self-reactive $\mathrm{T}$ cells from thymic deletion and thereby allow them to persist in the periphery (30).

In vitro studies suggest that the PTPN22 $1858 \mathrm{~T}$ allele provides less effective binding to Csk than the $\mathrm{C}$ allele and decreases the activation of $\mathrm{T}$ cell signals; as a result, carriers of the $\mathrm{T}$ allele are prone to autoimmune diseases (17). A correlation has been found between the PTPN22 C1858T gene polymorphism with T1DM in a meta-analysis of 11 European populations, with T2DM in an Estonian population, with HT in a German population and with several other autoimmune diseases $(16,17,30,31)$. Thyroid dysfunction is more common in T1DM patients than in T2DM patients (7). In recent publications, this frequency in T1DM has been reported as equal to that in an elderly group of T2DM patients $(6,7)$. There have been previous studies in which the T2DM and HT groups were examined separately, but to our knowledge no study has examined the PTPN22 C1858T gene polymorphism in a group with coexisting T2DM and HT; this is the first study performed in this group. We found that the frequency of the PTPN22 1858T allele was markedly lower in out Turkish cohort than the frequency in European populations in Finland, Estonia, Germany and Sweden. In the T2DM group in this study, the CT genotype and T alelle frequencies were lower than in Estonian (17), Finnish $(15,16)$ and Swedish (16) T2DM groups. In these T2DM patients, the frequency of the C1858T gene polymorphism was found to be statistically significantly different (15-17). Also, in the HT group in this study, we found that the frequencies of the CT genotype and $\mathrm{T}$ alelle were lower than in European populations $(30,31)$. In contrast to this study, Criswell et al. (32) reported that the second highest frequency of the T allele was $14.2 \%$ (27 patients) in 194 HT cases of Caucasian origin in America; as a result of the statistical analysis performed by comparing with the control group, the association between HT and the C1858T gene polymorphism was emphasized. In contrast to this, Dolts et al. (30) showed that $\mathrm{T}$ allele carriers were more frequent in the T1DM+HT group than in the T1DM group. Similarly, this study detected that $\mathrm{T}$ allele carriers were more frequent in the T2DM+HT group than in the T2DM; however, in the present study, $\mathrm{T}$ allele carriers and CT genotype frequencies were more frequent in the HT group than in the T2DM+HT group. Therefore, the combination of T2DM and HT is associated with $\mathrm{T}$ allele carriage in comparison to the T2DM group. We cannot make this association with the HT group.

Despite the existence of the TT genotype in Caucasian population studies, this genotype was not detected in any of the groups in this study. However, both the TT genotype and the T1858 allele are almost absent in African American and Asian populations. In some published papers, the $\mathrm{T}$ allele has been reported to be virtually absent in Japanese, Korean and Chinese populations (27). Recently, a meta-analysis suggested that the PTPN22 C1858T polymorphism is associated with AITD risk, especially in Caucasians than Asian and African American populations (33). These studies performed in different regions and populations have revealed the existence of ethnic differences in connection with the founder effect. A selection advantage in $\mathrm{Eu}-$ ropean populations and in individuals with Northern European origins is a possible reason for the T1858 variant distribution in the world; this evidence shows that host genetic factors are important $(12,27)$. Considering these results, it can be stated that the Turkish population is a transitional group between the populations of Asia and Europe regarding the frequency of distribution of the PTPN22 C1858T single nucleotide polymorphism.

The present study is the first to examine the association between the PTPN22 C1858T gene polymorphism and the T2DM+HT group. Although there were no statistically significant differences between the patient and control groups with regards to genotypes and allele frequencies $(p>0.05)$, the data of this study show that a statistically significant association exists between both the CT genotype and the T allele in female patients with coexistent $\mathrm{T} 2 \mathrm{DM}+\mathrm{HT}$ and that a statistically significant association exists between the CT genotype and the mean values of BMI and FT3 in the coexistent T2DM+HT patient group. So, the PTPN22 C1858T gene polymorphism is associated with female $\mathrm{T} 2 \mathrm{DM}+\mathrm{HT}$ patients, which may contribute to increased BMI and FT3 levels. The results of this study suggest that $\mathrm{T}$ allele carriers are more common in the T2DM+HT group and in females than in the T2DM group 
and males. Therefore, the coexistence of T2DM and HT and female gender are associated with increased $\mathrm{T}$ allele carriage in comparison to the T2DM and male groups.

As a limitation, the sample sizes of the experimental groups in this study were not large enough to evaluate a small impact from very low penetrance genes or SNPs. Further studies with larger cohorts of Turks and other ethnic populations are needed to clarify the etiopathophysiological and functional role of PTPN22 gene expression on T2DM, HT and coexistent T2D+HT.

Ethics Committee Approval: Ethics committee approval was received for this study from the ethics committee of Firat University (vide No. 05 dated: 24.06.2010)

Informed Consent: Written informed consent was obtained from patients who participated in this study.

Peer-review: Externally peer-reviewed.

Author contributions: Concept - F.B., H.E., H.D., D.E.; Design - F.B., D.E., H.E.; Supervision - F.B., H.E., D.E., F.A.Ö.; Resource - F.B., D.E., H.D., L.K., H.E.; Materials - F.B., H.D., L.K., F.A.Ö; Data Collection\&/or Processing - F.B., H.D., L.K., F.A.Ö.; Analysis\&/or Interpretation - F.B., D.E., H. E.; Literature Search - F.B., D.E., H.E.; Writing - F.B., D.E., F.A.Ö.; Critical Reviews - F.B., D.E., F.A.Ö.

Conflict of Interest: No conflict of interest was declared by the authors.

Financial Disclosure: This work was supported by Funds issued to Firat University Scientific Research Project (FUBAP, Turkey), No: 2099.

\section{REFERENCES}

1. Vondra K, Vrbikova J, Dvorakova K. Thyroid gland diseases in adult patients with diabetes mellitus. Minerva Endocrinol 2005;30:217-36.

2. Schroner Z, Lazurova I, Petrovicova J. Autoimmune thyroid diseases in patients with diabetes mellitus. Bratisl Lek Listy 2008;109:125-9.

3. Bindra A, Braunstein GD. Thyroiditis. Am Fam Physician 2006;15:1769-76.

4. Michels AW, Eisenbarth GS. Immunologic endocrine disorders. $\mathrm{J}$ Allergy Clin Immunol 2010;125:226-37. [CrossRef]

5. Fink H, Hintze G. Autoimmune thyroiditis (Hashimoto's thyroiditis): current diagnostics and therapy. Med Klin (Munich) 2010;105:485-93. [CrossRef]

6. Radaideh AR, Nusier MK, Amari FL, Bateiha AE, El-Khateeb MS, Naser AS, et al. Thyroid dysfunction in patients with type 2 diabetes mellitus in Jordan. Saudi Med J 2004;25:1046-50.

7. Kadiyala R, Peter R, Okosieme OE.Thyroid dysfunction in patients with diabetes: clinical implications and screening strategies. Int J Clin Pract 2010;64:1130-9. [CrossRef]

8. Rampersaud E, Damcott CM, Fu M, Shen H, McArdle P, Shi X, et al. Identification of novel candidate genes for type 2 diabetes from a genome-wide association scan in the Old Order Amish: evidence for replication from diabetes-related quantitative traits and from independent populations. Diabetes 2007;56:3053-62. [CrossRef]

9. Cantrell RA, Alatorre CI, Davis EJ, Zarotsky V, Le Nestour E, Carter GC, et al. A review of treatment response in type 2 diabetes: assessing the role of patient heterogeneity. Diabetes Obes Metab 2010;12:845-57. [CrossRef]

10. Shaw JE, Sicree RA, Zimmet PZ. Global estimates of the prevalence of diabetes for 2010 and 2030. Diabetes Res Clin Pract 2010;87:4-14.[CrossRef]

11. Jin W, Patti ME. Genetic determinants and molecular pathways in the pathogenesis of Type 2 diabetes. Clin Sci 2009;116:99-111. [CrossRef]

12. Jacobson EM, Tomer Y. The CD40, CTLA-4, Thyroglobulin, TSH receptor, and PTPN22 gene quintet and its contribution to thyroid autoimmunity: back to the future. J Autoimmun 2007;28:85-98. [CrossRef]
13. Levin L, Tomer Y. The etiology of autoimmune diabetes and thyroiditis: evidence for common genetic susceptibility. Autoimmun Rev 2003;2:377-86. [CrossRef]

14. Ridderstråle M, Groop L. Genetic dissection of type 2 diabetes. Mol Cell Endocrinol 2009;297:10-7. [CrossRef]

15. Andersen MK, Lundgren V, Turunen JA, Forsblom C, Isomaa B, Groop $\mathrm{PH}$, et al. Latent autoimmune diabetes in adults differs genetically from classical type 1 diabetes diagnosed after the age of 35 years. Diabetes Care 2010;33:2062-4. [CrossRef]

16. Cervin C, Lyssenko V, Bakhtadze E, Lindholm E, Nilsson P, Tuomi T, et al. Genetic similarities between latent autoimmune diabetes in adults, type 1 diabetes and type 2 diabetes. Diabetes 2008;57:1433-7. [CrossRef]

17. Douroudis K, Prans E, Haller K, Nemvalts V, Rajasalu T, Tillmann V, et al. Protein tyrosine phosphatase non-receptor type 22 gene variants at position 1858 are associated with type 1 and type 2 diabetes in Estonian population. Tissue Antigens 2008;72:425-30. [CrossRef]

18. Hu C, Zhang R, Wang C, Wang J, Ma X, Lu J, et al. PARG, KCNJ11, CDKAL1，CDKN2A-CDKN2B，IDE-KIF11-HHEX, IGF2BP2 and SLC30A8 are associated with type 2 diabetes in a Chinese population. PLoS One 2009;28;4:e7643.

19. Prokopenko I, McCarthy MI, Lindgren CM. Type 2 diabetes: new genes, new understanding. Trends Genet 2008;24:613-21. [CrossRef]

20. Tomer Y, Huber A. The etiology of autoimmune thyroid disease: a story of genes and environment. $J$ Autoimmun 2009;32:231-9. [CrossRef]

21. Kawasaki E, Awata T, Ikegami H, Kobayashi T, Maruyama T, Nakanishi $\mathrm{K}$, et al. Systematic Search for Single Nucleotide Polymorphisms in a Lymphoid Tyrosine Phosphatase Gene (PTPN22): Association Between a Promoter Polymorphism and Type 1 Diabetes in Asian Populations. Am J Med Genet A 2006;15;140:586-93. [CrossRef]

22. Zhang ZH, Chen F, Zhang XL, Jin Y, Bai J, Fu SB. PTPN22 allele polymorphisms in 15 Chinese populations. Int J Immunogenet 2008;35:433-7.[CrossRef]

23. Tfayli H, Arslanian S. Pathophysiology of type 2 diabetes mellitus in youth: the evolving chameleon. Arq Bras Endocrinol Metabol 2009;53:165-74. [CrossRef]

24. Zeyda M, Stulnig TM. Obesity, inflammation, and insulin resistance-a mini-review. Gerontology 2009;55:379-86. [CrossRef]

25. Usui I, Tobe K. The role of inflammation in the development of insulin resistance in type 2 diabetes. Nippon Rinsho 2011;69:555-62.

26. Brooks-Worrell B, Palmer JP. Immunology in the Clinic Review Series; focus on metabolic diseases: development of islet autoimmune disease in type 2 diabetes patients: potential sequelae of chronic inflammation. Clin Exp Immunol 2012;167:40-6. [CrossRef]

27. Vang T, Miletic AV, Bottini N, Mustelin T. Protein tyrosine phosphatase PTPN22 in human autoimmunity. Autoimmunity 2007;40:453-61. [CrossRef]

28. Lee YH, Rho YH, Choi SJ, Ji JD, Song GG, Nath SK, et al. The PTPN22 C1858T functional polymorphism and autoimmune diseases - a metaanalysis. Rheumatology 2007;46:49-56. [CrossRef]

29. Tomer Y, Menconi F. Type 1 diabetes and autoimmune thyroiditis: the genetic connection. Thyroid 2009;19:99-102. [CrossRef]

30. Dultz G, Matheis N, Dittmar M, Röhrig B, Bender K, Kahaly GJ. The protein tyrosine phosphatase non-receptor type 22 C1858T polymorphism is a joint susceptibility locus for immunthyroiditis and autoimmune diabetes. Thyroid 2009;19:143. [CrossRef]

31. Lee YH, Song GG. Meta-analysis of the family-based association between the PTPN22 C1858T polymorphism and type 1 diabetes. Mol Biol Rep 2013;40:211-5. [CrossRef]

32. Criswell LA, Pfeiffer KA, Lum RF, Gonzales B, Novitzke J, Kern M, et al. Analysis of families in the multiple autoimmune disease genetics consortium (MADGC) collection: the PTPN22 $620 \mathrm{~W}$ allele associates with multiple autoimmune phenotypes. Am J Hum Genet 2005;76:561-71. [CrossRef]

33. Luo L, Cai B, Liu F, Hu X, Wang L. Association of Protein Tyrosine Phosphatase Nonreceptor 22 (PTPN22) C1858T gene polymorphism with susceptibility to autoimmune thyroid diseases: a meta-analysis. Endocr J 2012;59:439-45. [CrossRef] 